\title{
PROFILE OF OCULAR TRAUMA IN A TERTIARY EYE HOSPITAL IN ANDHRA PRADESH
}

\author{
S. Pushpalatha1, M. Deepika²
}

${ }_{1}^{1}$ Tutor, Department of Ophthalmology, Rajiv Gandhi Institute of Medical Sciences, Srikakulam, Andhra Pradesh. ${ }^{2}$ Senior Resident, Department of Ophthalmology, Rajiv Gandhi Institute of Medical Sciences, Srikakulam, Andhra Pradesh.

\section{ABSTRACT}

\section{BACKGROUND}

The aim is to study aetiopathogenesis and various modes of ocular injuries and their management and outcome.

\section{MATERIALS AND METHODS}

This prospective study was conducted on 181 patients attending OPD or referred to our hospital with primary diagnosis of ocular trauma. Patients were thoroughly evaluated and treated appropriately.

\section{RESULTS}

Out of 181 patients, 114 (62.8\%) were male and 67 (37.2\%) were female. Average age of patients was found to be 31.6 years. Farmers formed the largest part of patients (23.75\%). Most common site of injury was road traffic accidents (28.72\%). Maximum number of patients (63.53\%) were found to be in 21-40 years age group. 95\% of the patients in our study did not use any protective eye wear. Open globe injury was seen in 98 (56\%) patients. Traumatic cataract was the most common complication (24.38\%). Visual acuity at presentation was found to be significantly associated with final visual prognosis.

\section{CONCLUSION}

Extensive health education campaign is necessary to reduce the burden of visual morbidity and ensure prevention and early treatment.

\section{KEYWORDS}

Ocular Trauma, Blunt Ocular Trauma, Penetrating Ocular Injury, Perforating Ocular Injury, Intraocular Foreign Body.

HOW TO CITE THIS ARTICLE: Pushpalatha S, Deepika M. Profile of ocular trauma in a tertiary eye hospital in Andhra Pradesh. J. Evolution Med. Dent. Sci. 2017;6(24):1972-1974, DOI: 10.14260/jemds/2017/432

\section{BACKGROUND}

Ocular trauma is a significant cause of visual loss, especially in lower socioeconomic strata and underdeveloped countries. The effects of such injuries are much more severe than in any other part of the body, partly because of delicacy of the ocular tissues and partly because a trauma which elsewhere would cause little and temporary inconvenience, can readily result in permanent blindness. Ocular injuries therefore have a huge social and economic impact leading to human unhappiness, economic insufficiency and monetary loss. Ocular trauma is an important cause of preventable monocular blindness and visual impairment in the world. $(1,2,3)$

\section{Aim}

To study aetiopathogenesis and various modes of ocular injuries, age and sex incidence of ocular injuries, management and outcome of ocular injuries.

\section{MATERIALS AND METHODS}

Cases of ocular injuries attending our hospital were studied. Nature of injuries, aetiopathogenesis, age and sex incidence are analysed. Management and outcome were tabulated.

Financial or Other, Competing Interest: None.

Submission 04-01-2016, Peer Review 27-05-2016,

Acceptance 03-06-2016, Published 22-03-2017.

Corresponding Author:

Dr. S. Pushpalatha,

D. No. 18-141, Port Colony,

Madhurawada, Visakhapatnam,

Andhra Pradesh.

E-mail: siripurapu1977@gmail.com

DOI: $10.14260 /$ jemds $/ 2017 / 432$

\section{METHODOLOGY}

A prospective study was conducted on all patients attending ophthalmology department from December 2010 to November 2012 with primary diagnosis of ocular trauma and patients referred from emergency department and eye care centres from peripheries were included in the study, which included 181 patients. Trivial injuries like superficial foreign bodies, adnexal injuries without ocular involvement and without visual impairment and operated eyes where the clinical findings are not traumatic in nature were excluded. Children less than five years and unconscious patients who are not cooperative for examination were excluded from the study. Demographic variables of each patient including address, occupation and literacy status were noted. A complete history of the mishap, its nature and place of injury were recorded. Information on whether the patient was using protective eyewear at the time of injury and whether he/she was intoxicated at the time of injury was collected using structured questionnaire. Initial BCVA, eyelid and adnexal injuries, subconjunctival haemorrhage and conjunctival lacerations, presence or absence of corneal or sclera perforation, hyphaema, iris injuries and RAPD were included in the examination.

A detailed workup of all patients including slit lamp biomicroscopy, direct and indirect ophthalmoscopy was done. B-scan was done where media prevented fundus evaluation in closed globe injuries. Intraocular pressure was recorded in all closed globe injuries. Gonioscopy was done in all closed globe injuries. The trauma cases were classified based on standardised Birmingham Eye Trauma Terminology (BETT).(4) The cases were managed on the basis of standard guidelines,(5) while some cases were referred to higher centres 
for further management. The visual outcome was recorded at the time of discharge. The cases were followed up and complications were recorded. The results thus obtained are analysed, discussed and compared with existing studies in literature.

\section{RESULTS}

A total of 206 patients were examined out of which 181 were included in the current study; the remaining 25 were lost in followup. Incidence of ocular trauma was found to be $0.33 \%$. Out of 181 patients, 114 (62.8\%) were male and 67 (37.2\%) were female ( $p$-value $<0.0001)$. Average age of patients was found to be 31.6 years. Right eye was involved in 91 (50.25\%) patients, left eye in $85(46.96 \%)$, while in $5(2.76 \%)$ patients both eyes were involved. Farmers formed the largest part of patients $(23.75 \%)$, followed by daily wage labourers and students $(17.67 \%)$ each. Housewives were least commonly affected (3.3\%) group. Most common site of injury was road traffic accidents $(28.72 \%)$, followed by injuries at farm (28.17\%). Sports injuries also accounted for a significant number of cases, i.e., $18.78 \%$. Injuries due to fireworks formed a noticeable part of injuries (12\%) and most of them were males (74\%). Maximum number of patients (63.53\%) were found to be in 21-40 years age group (p-value <0.0001). 95\% of the patients in our study did not use any protective eye wear. Mechanical injury was most common (96.7\%); chemical injuries formed the remaining 3.3\%. Open globe injury was seen in 98 (56\%) patients, the remaining 77 (44\%) patients had closed globe injury. This difference was not statistically significant (p-value 0.1987). 93\% had lacerations, while the remaining had globe rupture and/or intraocular foreign bodies. Zone 1 injury was found to be most common (61\%) followed by zone $2(25 \%)$ and zone $3(14 \%)$. Subconjunctival haemorrhage $(40 \%)$ was the most common clinical manifestation followed by traumatic vitreous haemorrhage (28.9\%). Other manifestations are listed in table 1.

\begin{tabular}{|c|c|c|}
\hline Type of Injury & No. of Cases & $\mathbf{\%}$ \\
\hline SCH & 34 & 40 \\
\hline Intracorneal Foreign body & 8 & 0.96 \\
\hline Conjunctival Lacerations & 18 & 21.6 \\
\hline TR. Mydriasis & 6 & 7.2 \\
\hline Macular Oedema & 4 & 4.81 \\
\hline TR. Hyphaema & 23 & 27.71 \\
\hline TR. Cataract/Subluxation & 18 & 21.6 \\
\hline TR.VH & 22 & 28.91 \\
\hline Orbital Fractures & 6 & 7.2 \\
\hline Orbital Haemorrhage & 3 & 3.6 \\
\hline Optic Nerve Avulsion & 1 & 1.2 \\
\hline Total & $\mathbf{8 3}$ & $\mathbf{1 0 0}$ \\
\hline Table 1. Manifestations following & $\mathbf{0 c u l}$ Trauma \\
\hline
\end{tabular}

Table 1. Manifestations following Ocular Trauma

Anatomical location of injuries are listed in table 2.

\begin{tabular}{|c|c|c|c|c|}
\hline Location & Zone I & Zone II & Zone III & $\mathbf{\%}$ \\
\hline Conjunctiva & 59 & 0 & 0 & 76.62 \\
\hline Sclera & 3 & 0 & 0 & 3.8 \\
\hline Cornea & 8 & 0 & 0 & 10.38 \\
\hline AC & 0 & 13 & 0 & 16.88 \\
\hline IRIS & 0 & 8 & 0 & 10.38 \\
\hline Pupil & 0 & 24 & 0 & 31.16 \\
\hline
\end{tabular}

\begin{tabular}{|c|c|c|c|c|}
\hline Lens & 0 & 18 & 0 & 23.37 \\
\hline CB & 0 & 0 & 9 & 11.68 \\
\hline Choroid & 0 & 0 & 3 & 3.8 \\
\hline Vitreous & 0 & 0 & 21 & 27.27 \\
\hline Retina & 0 & 0 & 3 & 3.8 \\
\hline \multicolumn{2}{|r|}{ Table 2. Anatomical Location of Injuries } \\
\hline
\end{tabular}

\begin{tabular}{|c|c|c|}
\hline & No. of Cases & \% \\
\hline Corneal Opacity & 23 & 12.70 \\
\hline Blood Staining of Cornea & 2 & 1.10 \\
\hline Adherent Leucoma & 5 & 2.76 \\
\hline Traumatic Cataract & 45 & 24.86 \\
\hline Choroidal Rupture & 2 & 1.10 \\
\hline Vitreous Haemorrhage & 19 & 10.42 \\
\hline Limbal Ischaemia & 1 & 0.05 \\
\hline Retinal Detachment & 3 & 1.65 \\
\hline Sec. Glaucoma & 2 & 1.10 \\
\hline Lagophthalmos/Punctal eversion & 3 & 1.65 \\
\hline Optic Nerve Avulsion & 1 & 0.5 \\
\hline Phthisis & 5 & 2.76 \\
\hline Total & $\mathbf{1 8 1}$ & $\mathbf{1 0 0}$ \\
\hline Table 3. Complications of Ocular Trauma \\
\hline \multicolumn{2}{|c}{} \\
\hline \multicolumn{2}{|c|}{}
\end{tabular}

Scleral involvement was seen in $48.97 \%$ of patients. Time interval between injury and ophthalmology consultation was 24 hours or less in $79.5 \%$ of cases; within 72 hours in $12.7 \%$ and more than 72 hours in $7.73 \%$. Delayed presentation was found to be common in patients from rural areas. Conservative management was advised for $48.61 \%$ of patients, while $51.38 \%$ underwent surgery. Traumatic cataract was the most common (24.38\%) complication, followed by corneal opacity $(12.7 \%)$, listed in table 3.

Visual acuity at presentation was found to be significantly associated with final visual prognosis ( $p$ Value $<0.0001$ ). Orbital cellulitis and endophthalmitis were seen in one patient $(0.55 \%)$ each. Blindness defined as final visual acuity less than $3 / 60(6)$ was seen in $24.3 \%$ of the patients.

\section{DISCUSSION}

Incidence of ocular trauma in our study was found to be $0.33 \%$ compared to $1.6 \%$ in other studies.(7) The difference can be explained by the fact that ours is a hospital based study with a duration of only 2 years. Male patients were significantly more in number than female patients.(3),(8),(9),(10),(11),(12),(7),(13),(14) Right eye was more commonly involved than left eye.(9) Farmers were the most common occupational group affected(10) whereas labourers, the second most common group in our study constituted most common affected group in some other studies.(12),(7),(14) Road traffic accidents were most common cause of injuries followed closely by injuries at farm. This difference was not clinically significant. Most common age at presentation was found to be in 31-40 years group which correlates with other studies.(3),(8),(12) In the current study, majority of patients are illiterate leading to lack of awareness about the preventive measures and immediate attention to the ocular injury. This corresponds to findings of S Vats et al,(3) Singh et al( ${ }^{(9)}$ and S.Krishnaiah et al.(11) Another explanation for this is better treatment seeking behaviour in literates. $95 \%$ of the patients in our study did not use any protective eye wear, similar to the findings of S. Vats, (3) S. Krishnaiah et al.(11) $18 \%$ 
had sports related injury compared to $12 \%$ in the study by Barr A et al(15) and the most common sport involved was cricket when compared to football(15) as cricket is more popular in our region. Injuries due to firecrackers were seen mostly in males similar to the observations in other studies.(16),(17) Open globe injuries were found to be more common than closed globe injuries correlating with some other studies(9) but contradicting some other studies.(3),(10) The reason for this is that ours was a hospital based study that attracted patients with need for emergency repair as compared to other studies that were population based. Zone 1 injury was found to be most common similar to Singh et al.(9) Cause of injury endophthalmitis was seen in $0.55 \%$ cases. S. Krishniah et al(11) noted $33.3 \%$ of traumatic cataract, $33.33 \%$ corneal scars and $8 \%$ phthisis. In the present study, anterior segment complications include $12.70 \%$ corneal opacities and $24.86 \%$ traumatic cataracts. Among the posterior segment complications, vitreous haemorrhage was seen in $10.42 \%$. Retinal detachment was seen in $1.65 \%$, compared to $11.3 \%$ in study by Singh et al(9) and found to be significantly more in open globe injury. ${ }^{(9)} 2.76 \%$ of patients had phthisis bulbi. Visual acuity at presentation was found to be significantly associated with final visual prognosis corroborating the study by Esmaeli B et al.(18),(19) No cases of sympathetic ophthalmitis has been encountered during the study period. This can be explained by appropriate management and timely administration of steroids, which prove useful in preventing the dreaded complications.

\section{CONCLUSION}

In the light of the consequences of ocular injuries described earlier the following preventive measures have to be taken. They are: 1 . Health education camps in schools 2. Media propaganda to prevent injuries from fireworks. 3. Emphasise the need to use protective measures in industrial workers. 4 . Prevention of road traffic accidents. 5. Educate the parents to keep the sharp objects away from the children. 6 . Check on the vehicle drivers who drive under the influence of alcohol. In our study, delayed presentation is noted from the rural settings, so it is very important to educate the patients regarding health seeking behaviour, because early and meticulous repair will give good results and reduces the visual morbidity.

\section{REFERENCES}

[1] Katz J, Tielsch JM. Lifetime prevalence of ocular injuries from the Baltimore eye survey. Arch Ophthalmic 1993;111(11):1564-8.

[2] Schein OD, Hibberd P, Shingleton BJ, et al. The spectrum and burden of ocular injury. Ophthalmology 1988;95(3): 300-5.

[3] Vats S, Murthy GV, Chandra M, et al. Epidemiological survey of ocular trauma in an urban slum population in Delhi, India. Indian J Ophthalmol 2008;56(4):313-6.
[4] Kuhn F, Morris R, Witherspoon CD, et al. The Birmingham eye trauma terminology system (BETT). J Fr Ophtalmol 2004;27(2):206-10.

[5] Leucona K. Assessing and managing eye injuries. Community Eye Health 2005;18(55):101-4.

[6] Thylefors B, Negral AD, Pararajasegaram R, et al. Global data on blindness. Bull World Health Organ 1995;73(1): 115-21.

[7] Wong TY, Klein BE, Klein R. The prevalence and 5 year incidence of ocular trauma the beaver dam eye study. Ophthalmology 2000;107(12):2196-202.

[8] Malla BK. Structural changes in ocular trauma and the visual outcome. Kathmandu University Medical Journal 2003;2(6):113-8.

[9] Singh DV, Sharma YR, Azad RV, et al. Profile of ocular trauma at tertiary eye centre. JK Science 2005;7(1):149.

[10] Nirmalan PK, Katz J, Tielsch JM, et al. Ocular trauma in a rural south Indian population: the Aravind comprehensive eye survey. Ophthalmology 2004;111(9): 1778-81.

[11] Krishnaiah S, Nirmalan PK, Shamanna BR, et al. Ocular trauma in a rural population of southern India: the Andhra Pradesh eye disease study. Ophthalmology 2006;113(7):1159-64.

[12] Dandona L, Dandona R, Srinivas M, et al. Oculat trauma in an urban population in southern India: the Andhra Pradesh eye disease study. Clin Exp Ophthalmol 2000;28(5):350-6.

[13] Wong TY, Tielsch JM. A population based study on the incidence of severe ocular trauma in Singapore. Am J Ophthalmol 1999;128(3):345-51.

[14] Dandona R, Dandona L. Review of findings of the Andhra Pradesh eye disease study: policy implications for eye-care services. Indian J Ophthalmol 2001;49(4):215-34.

[15] Barr A, Baines P, Desai P, et al. Ocular sports injuries: the current picture. Br J Sports Med 2000;34(6):456-8.

[16] Malik A, Bhala S, Arya SK, et al. Five-year study of ocular injuries due to fireworks in India. Int Ophthalmol 2013;33(4):381-5.

[17] Kumar R, Puttana M, Sriprakash KS, et al. Firecracker injuries during Deepavali festival: a case series. Indian J Ophthalmol 2010;58(2):157-9.

[18] Esmaeli B, Elner SG, Schork MA, et al. Visual outcome and ocular survival after penetrating trauma a clinicopathologic study. Ophthalmology 1995;102(3): 393-400.

[19] Cao H, Liping L, Zhang M. Epidemiology of patients hospitalized for ocular trauma in the chaoshan region of China, 2001-2010. PLoS ONE 2012;7(10):e48377. 